\title{
Common variable immunodeficiency disorders: What generalists should know
}

\author{
A C Jeevarathnum, ${ }^{1}$ MB BCh, FCPaeds (SA), Dip Allergy (SA), MMed (Paeds), Eur Resp Diploma, Cert Paed Pulm (SA); \\ A van Niekerk, ${ }^{1} \mathrm{MB}$ BCh, MMed (Paeds); J Kriel, ${ }^{2} \mathrm{MB}$ ChB, MMed (Int Med), FCP (SA); R J Green, ${ }^{3}$ PhD, DSc \\ ${ }^{1}$ Department of Paediatric Pulmonology, Faculty of Health Sciences, University of Pretoria, South Africa \\ ${ }^{2}$ Sandton Allergy and Immunology Centre, Johannesburg, South Africa \\ ${ }^{3}$ Department of Paediatrics and Child Health, Faculty of Health Sciences, University of Pretoria and Steve Biko Academic Hospital, Pretoria, South Africa
}

Corresponding author: A C Jeevarathnum (acjeevarathnum@gmail.com)

\begin{abstract}
Primary immune deficiency disorders (PIDDs) are common and underdiagnosed. Predominant antibody deficiencies (PADs) are the most common type of immune deficiency and comprise 55\% of the immune deficiencies diagnosed. ${ }^{[1]}$ Although immunoglobulin A (IgA) deficiency remains the most common type of PID, common variable immunodeficiency disorders remain the most common symptomatic PID for which medical therapy is sought.

Keywords. immune deficiency; common variable; predominant antibody deficiency.
\end{abstract}

Afr J Thoracic Crit Care Med 2021;27(3):112-116. https://doi.org/10.7196/AJTCCM.2021.v27i3.228

Hypogammaglobulinaemia is the hallmark of common variable immunodeficiency disorders (CVID), where the loss of B-cell function is the causative immune defect observed in all patients. CVID is not a single disease but rather a heterogeneous group of primary antibody failure syndromes, defined by hypogammaglobulinaemia, increased susceptibility to recurrent and chronic infections, and impaired functional antibody responses. ${ }^{[1]}$ Biochemically, this common phenotype manifests with reduced levels of immunoglobulin $\mathrm{G}(\mathrm{IgG})$ and either low IgA and/or low IgM, together with an impaired antibody response to vaccines. ${ }^{[2-4]}$

Individuals with CVID are susceptible to recurrent infections with mainly encapsulated extracellular organisms and are more prone to autoimmune diseases, lymphoproliferative disorders, and malignancies. Usually, the diagnosis is made between the ages of 20 and 40 years; however, up to $20 \%$ of patients may present before the age of 20 years. The onset of clinical manifestations and laboratory findings do not always coincide and can occur from early childhood to caducity. ${ }^{[3]}$

In this review article, we review the latest literature on CVID, particularly the epidemiology, pathophysiology, clinical features, differential diagnosis, diagnostic criteria, and association with autoimmune and lymphoproliferative disorders. The difference in presentation between adults and children is explored and basic treatment strategies are discussed.

The purpose of this overview is to increase awareness of this heterogeneous group of disorders, facilitating early diagnosis and appropriate management to mitigate the devastating sequelae of untreated CVID.

\section{Epidemiology}

CVID was first described in 1954 in a 39-year-old woman with a gammaglobulinaemia and numerous pulmonary and gastrointestinal complications. ${ }^{[2]}$ CVID has no gender predilection and occurs at an incidence of 1:10 000 to 1:50 000 in a population, ${ }^{[5-7]}$ and has a bimodal age distribution with diagnostic peaks in childhood and early adult life. ${ }^{[8]}$ One-fifth of patients are diagnosed before the age of 20 years. ${ }^{[8]}$ It certainly is the most common primary immune deficiency disorder (PIDD) detected in the adult population. ${ }^{[9]}$ There is usually a delay of $4-6$ years before the diagnosis is confirmed because of the heterogeneous array of clinical presentations. ${ }^{[5,9,10]}$

\section{Aetiology}

Most cases of CVID are sporadic. There is, however, a genetic basis in $10-20 \%$ of cases. ${ }^{[5]}$ Patients who develop CVID because of a genetic predisposition usually inherit the disorder in an autosomal dominant fashion. ${ }^{[5,9]}$ Research has shown several HLA associations. ${ }^{[5,9]}$ It has been estimated that $15 \%$ of patients with CVID will have a first-degree relative with IgA deficiency or CVID. In addition, there might be a genetic association between CVID and IgA deficiency, with both disorders reflecting variable expression of a common genetic defect. ${ }^{\left[{ }^{[5]}\right.}$

\section{Pathophysiology}

CVID involves immune dysfunction of $\mathrm{T}$ and $\mathrm{B}$ cells in addition to dendritic cells. The basic pathophysiological mechanism underlying the disorder is the failure of B cells to differentiate into plasma cells, resulting in reduced production of Igs. The absolute number of $\mathrm{B}$ cells might be normal, but the cells are dysfunctional. Because of the reduction in production of Igs, the adaptive immune system is compromised, and the patients are prone to developing recurrent infections. The more intricate details of the pathophysiology of the disorder are beyond the scope of this article.

\section{Clinical manifestations}

Most patients with CVID will have at least one of the varied clinical presentations: infection and lymphoproliferation or autoimmunity, but 
as noted before, the phenotype is varied and may range from bacterial infections only to severe illness such as a combined immunodeficiency.

Patients may also present only with autoimmune disease, granulomatous disorders, or enteropathy with no evidence of recurrent bacterial infections.

The most common clinical manifestations include six categories, each of which will be discussed separately. A summary of clinical manifestations and complications is provided in Table $1 .^{[4,5,9,11,12]}$

It should be noted that not all patients with CVID will develop complications owing to immune dysregulation. Some patients develop infection only phenotype (33 - 80\%) and may also develop infectionrelated structural complications such as bronchiectasis but not autoimmunity, interstitial lung disease, granulomatous disease, liver and gastrointestinal inflammatory disease, and lymphoid hyperplasia or cancer. ${ }^{[2,3,13]}$

\section{Recurrent and unusual infections}

Most patients with CVID have a history of acute or chronic sino-

\begin{tabular}{|c|c|}
\hline Infections & Otitis media \\
\hline (Predominantly & Sinusitis \\
\hline respiratory and & Pneumonia \\
\hline \multirow[t]{3}{*}{ gastrointestinal) } & Recurrent pneumonia \\
\hline & Gastritis \\
\hline & Diarrhoea \\
\hline Chronic pulmonary & Bronchiectasis \\
\hline \multirow[t]{4}{*}{ conditions } & Bronchiolitis obliterans \\
\hline & Asthma \\
\hline & Granulomatous infiltrations \\
\hline & Lymphocytic interstitial pneumonitis \\
\hline Diffuse & Noncaseating granulomatous of the \\
\hline granulomatous & lung, liver, spleen, bone marrow, lymph \\
\hline disease & nodes, skin, kidney, eyes and brain. \\
\hline Gastrointestinal & Infective diarrhoea \\
\hline \multirow[t]{5}{*}{ disease } & Chronic diarrhoea \\
\hline & Malabsorption \\
\hline & Inflammatory bowel disease \\
\hline & Autoimmune hepatitis \\
\hline & Primary biliary cirrhosis \\
\hline \multirow[t]{2}{*}{ Liver disease } & Nodular regenerative hyperplasia \\
\hline & Autoimmune hepatitis \\
\hline \multirow[t]{6}{*}{ Autoimmune } & Autoimmune haemolytic anaemia \\
\hline & Immune thrombocytopaenia \\
\hline & Seronegative Rheumatoid arthritis \\
\hline & Pernicious anaemia, alopecia, vitiligo \\
\hline & Sjogrens syndrome \\
\hline & Uveitis, vasculitis, Sicca syndrome, SLE \\
\hline \multirow[t]{2}{*}{ Malignancy } & Lymphoma \\
\hline & Gastric carcinoma \\
\hline
\end{tabular}

pulmonary infections, particularly sinusitis, otitis media and pneumonia. ${ }^{[14-16]}$ This is usually caused by encapsulated bacteria, ${ }^{[14-16]}$ and up to $75 \%$ of patients usually have an episode of communityacquired pneumonia prior to diagnosis. It is common to find patients who present with recurrent episodes of pneumonia. ${ }^{[17,18]}$ The most common pathogens include Streptococcus pneumoniae, Haemophilus influenzae, Moraxella catarrhalis, Staphylococcus aureus and Pseudomonas aeroginosa. Mycoplasma is also an important intracellular pathogen in patients with atypical respiratory tract infections. CVID is unlike PIDs that are prone to opportunistic infections with fungal or viral pathogens.

Patients with CVID $(10-40 \%)$ are prone to gastrointestinal infections with pathogens such as Giardia lamblia, Campylobacter jejuni and Salmonella spp., and Giardia is the most common pathogen. ${ }^{[19]}$ Helicobacter pylori is an important pathogen in CVID and causes chronic active gastritis. ${ }^{[20]}$

Unusual urinary and cervical infections owing to Ureaplasma urealyticum as well as meningoencephalitis or dermatomyositis-like syndrome caused by enteroviruses have been described in undiagnosed and untreated patients. ${ }^{[1,22]}$

\section{Chronic pulmonary conditions}

It is estimated that between $37.5 \%$ and $73 \%$ of patients with CVID have bronchiectasis and it has been shown that patients with low levels of IgM are at increased risk of developing recurrent pneumonia and bronchiectasis. ${ }^{[23,24]}$

Airway inflammation is commonly seen and may progress to obstructive or restrictive disease given time. Asthma has been observed in $9-15 \%$ of patents with CVID. The actual aetiology of asthma in patients with CVID is largely unknown.

Mediastinal lymphadenopathy is common in CVID. Nonnecrotising granulomas have been described in $8-22 \%$ of patients with CVID; these non-necrotising granulomas differ from those from sarcoidosis as they are not located peri-lymphatically. Sarcoidosis is usually associated with hyper-gammaglobulinaemia. ${ }^{[25-27]}$ Lymphocytic interstitial pneumonitis has also been reported.

\section{Gastrointestinal disease}

There is a high incidence of inflammatory and infectious gastrointestinal disorders in patients with CVID. ${ }^{[28]}$ Mild watery diarrhoea is common and occurs periodically. More severe clinical disease with malabsorption and weight loss are well described and occur in $10 \%$ of cases. Gastrointestinal pathology may include nodular lymphoid hyperplasia and autoimmune hepatitis progressing to portal hypertension.

A challenging form of chronic small bowel inflammation and CVID-associated autoimmune enteropathy (AIE) occurs in up to $12 \%$ of patients presenting with unexplained persistent diarrhoea, malabsorption of minerals and fat-soluble vitamins, steatorrhoea, and weight loss. These patients often have vitamin A deficiency with added suppression of Ig production. Mild hepatomegaly and an elevated level of alkaline phosphatase is also seen in CVID. ${ }^{[29-31]}$

\section{Granulomatous or polyclonal lymphocytic infiltrative complications}

Some patients $(10-25 \%)$ with CVID develop granulomatous or lymphoproliferative diseases. The mean age of diagnosis is 
20 - 40 years. Granulomatous lesions can affect any region of the body, but most commonly affect the lungs. Patients present with chronic shortness of breath and cough, which is not related to asthma. ${ }^{[8]}$

\section{Autoimmunity}

It has been suggested that up to $30 \%$ of patients with CVID will experience an autoimmune process. Autoimmune disease was the sole clinical finding at the time of diagnosing CVID in $2.3 \%$ of patients. ${ }^{[29]}$ Common autoimmune entities seen in CVID patients include autoimmune cytopaenias such as immune thrombocytopaenic purpura (ITP), autoimmune haemolytic anaemia (AIHA), combination of ITP and AIHA (Evan's syndrome), seronegative rheumatoid arthritis (RA), pernicious anaemia, inflammatory bowel disease, Sjögren's syndrome, uveitis, vasculitis, thyroiditis, alopecia, vitiligo, primary biliary cirrhosis, and sicca syndrome or systemic lupus erythematosus. ${ }^{[5,29]}$

Common autoimmune diseases such as type I diabetes mellitus, seropositive RA, psoriasis, celiac and hypothyroidism are not increased in patients with CVID.

Not only is the underlying pathogenesis of CVID poorly understood, but the management of concurrent autoimmunity often becomes a challenging task. It is very important to emphasise that autoimmunity may be the presenting feature of CVID without any evidence of recurrent infections characteristic of a PIDD. ${ }^{[32]}$

There seems to be a higher prevalence of autoimmune processes in patients with a paucity of switched memory B cells (CD27+, IgMIgD-). Another characteristic feature predictive of an autoimmune process in patients with CVID is the presence of granulomatous infiltrations in the lungs, nodes or other organs.

CVID patients with autoimmune diseases are treated using higher doses of immunoglobulin replacement therapy (IRT), and when immune suppressive drugs are administered, it is advised that lower doses and shorter courses are given to prevent the development of opportunistic infections considering the underlying PIDD.

\section{Malignancy}

The lifetime risk of all types of malignancies in adults with CVID is around $6-9 \% \cdot{ }^{[33]}$ CVID patients are at tenfold increased risk of developing solid or haematological malignancies. ${ }^{[33]}$ Patients with lymphoma typically have a childhood onset and those with gastric tumours present later in adulthood, particularly in the fourth decade of life. The most common type of malignancy reported in patients with CVID is non-Hodgkin's lymphoma. ${ }^{[34]}$

\section{Making a diagnosis}

There is no single test or biochemical marker available to diagnose CVID. The diagnosis is made by a constellation of clinical features and several laboratory investigations. It is the combined result of these tests from which a diagnosis can be made. There are more common genetic disorders that manifest with CVID. Testing for this is possible but expensive. However, diagnosis is not dependent on genetic testing only.

The diagnosis of CVID rests on exclusion of other causes of hypogammaglobulinaemia (Table 2 ).

\begin{tabular}{|c|c|}
\hline Drug-induced & Antimalarial agents \\
\hline \multirow{14}{*}{$\begin{array}{l}\text { Single gene and other } \\
\text { defects }\end{array}$} & Captopril \\
\hline & Phenytoin, carbamazepime \\
\hline & Anti-CD20 mAbs: Rituximab \\
\hline & Glucocorticoids \\
\hline & Sulfasalazine \\
\hline & Ataxia telangiectasia \\
\hline & AR forms of SCID and other combined \\
\hline & immunodeficiency \\
\hline & Hyper-IgM syndromes \\
\hline & Transcobalamin II deficiency and \\
\hline & hypogammaglobulinaemia \\
\hline & $\mathrm{X}$-linked agammaglobulinemia \\
\hline & X-linked Lymphoproliferative disorder \\
\hline & (EBV-associated) \\
\hline \multirow{4}{*}{$\begin{array}{l}\text { Chromosomal } \\
\text { abnormalities }\end{array}$} & X-linked SCID \\
\hline & Chromosome 18q-syndrome \\
\hline & Monosomy 22 \\
\hline & Trisomy 8 \\
\hline \multirow{3}{*}{ Infectious diseases } & Trisomy 21 \\
\hline & HIV \\
\hline & EBV \\
\hline \multirow{5}{*}{ Malignancies } & Congenital infections with CMV/ \\
\hline & rubella/toxoplasma \\
\hline & Chronic lymphocytic leukaemia \\
\hline & Non-Hodgkin’s lymphoma \\
\hline & Monoclonal gammopathy \\
\hline \multirow{4}{*}{$\begin{array}{l}\text { Other systemic } \\
\text { disorders causing } \\
\text { excessive loss of } \\
\text { immunoglobulins }\end{array}$} & Nephrotic syndrome \\
\hline & Severe burns \\
\hline & Lymphangiectasia \\
\hline & Protein-losing enteropathy \\
\hline
\end{tabular}

Demonstration of hypogammaglobulinaemia and defective specific antibody responses or levels is imperative. It is difficult to make this diagnosis in children younger than 4 years of age as the hypogammaglobulinaemia in this age group is most likely because of a transient hypogammaglobulinaemia of infancy (THI). However, patients with THI can develop CVID, but the distinction between the two is difficult.

The American Academy of Asthma, Allergy, and Immunology in collaboration with the European Academy of Asthma, Allergy and Immunology and World Allergy Organization published a consensus document on the diagnosis of CVID in 2015. ${ }^{[4,35]}$ According to the document, a diagnosis of CVID can be made if the following criteria are met:

- Age $>2$ years

- At least one clinical manifestation (infection, autoimmunity, lymphoproliferation) 
- Demonstration of hypogammaglobulinaemia on two occasions at least 3 weeks apart as below:

- Marked decrease of IgG levels at least 2 standard deviations below mean for age and either;

- Low IgA and/or IgM

- Low specific antibodies, absent isohaemaglutinins and/or failure to exert an adequate vaccine response, or significant waning of vaccine levels

- Exclusion of defined causes for hypogammaglobulinaemia according to a list of differential diagnoses (Table 2).

\section{Management}

The most important part of managing these patients is to make a diagnosis. The astute physician will be confronted with several clinical syndromes and recurrent infections and making the diagnosis will require a high index of suspicion.

Once the diagnosis has been made, the physician can explore IRT, which is the mainstay of management of patients with CVID.

The aim of IRT is clinical improvement and resolution of recurrent infections, either by subcutaneous or intravenous immunoglobulin replacement routes. One usually needs to maintain the trough IgG level at a level $>400-500 \mathrm{mg} / \mathrm{dL}$ and, to achieve this, doses of $400-600 \mathrm{mg} / \mathrm{kg}$ every 3 - 4 weeks are required, with higher doses needed for established complications such as bronchiectasis with a trough level of no less than $700-800 \mathrm{mg} / \mathrm{dL} .{ }^{[4]}$

Prophylactic antibiotics are often prescribed for patients with CVID. The benefit of this strategy is still under review and the jury is out on the long-term sequelae. Options of prophylactic antibiotics include trimethoprim-sulfamethoxazole or macrolides and there are various regimens described.

The prognosis of patients with CVID depends on several factors including the frequency of infections, structural lung damage and development of autoimmunity and malignancy.

\section{Conclusion}

CVID is the most common symptomatic PIDD. More so, it is the most common PIDD presenting in adulthood. Symptoms are usually heterogeneous and nonspecific. Patients present with recurrent infections caused mostly by encapsulated extracellular bacteria. Viral and fungal opportunistic infections do not often occur in patients with CVID. Diagnosis of CVID is by exclusion and molecular testing is not considered necessary for diagnosis and can be considered if monogenetic disease is suspected. Clinicians must be aware that these patients are prone to autoimmune diseases, lymphoproliferative disorders, and malignancies. It must be noted that CVID at present is only treated symptomatically. Management principles involve the use of IRT and judicious use of prophylactic antibiotics.

\section{Declaration. None.}

Acknowledgements. None.

Author contributions. ACJ conceptualised the study, collated the literature and wrote the manuscript. JK assisted from an adult CVID perspective. AvN and RJG provided critical review and editing of the manuscript. All authors approved the final version of the manuscript for publication.

Funding. None.

Conflicts of interest. None.
1. Rezaei N, Bonilla F, Seppanen M, et al. Introduction on primary immunodeficiency diseases. In: Rezaei N, Aghomohammadi A, Notarengelo L, eds. Primary immunodeficiency diseases definition, diagnosis, and management. 2nd ed. Berlin: Springer, 2017:1-82.

2. Chapel H, Lucas M, Patel S, et al. Confirmation and improvement of criteria for clinical phenotyping in common variable immunodeficiency disorders in replicate cohorts. J Allergy Clin Immunol 2012;130(5):1197-1198. https://doi.org/10.1016/j. jaci.2012.05.046

3. Malphettes M, Gerard L, Carmagnat M, et al. Late-onset combined immune deficiency: A subset of common variable immunodeficiency with severe $\mathrm{T}$ cell defect. Clin Infect Dis 2009;49:1329-1338. https://doi.org/10.1086/606059

4. Bonilla FA, Barlan I, Chapel H, et al. International Consensus Document (ICON): Common variable immunodefiency disorders. J Allergy Clin Immunol Pract 2016;4(1):38-59. https://doi.org/10.1016/j.jaip.2015.07.025

5. Agamohammadi A, Plebani A, Lougaris V, et al. Predominantly antibody deficiencies. In: Rezaei N, Aghomohammadi A, Notarangelo L, eds. Primary Immunodeficiency Diseases: Definition, Diagnosis, and Management. 2nd ed. Heidelberg: Springer, 2017:183-244

6. Hammarstrom L, Vorechovsky I, Webster D. Selective IgA deficiency and common variable immune deficiency. Clin Exp Immun 2000;120:225-231. https://doi. org/10.1046\%2Fj.1365-2249.2000.01131.x

7. Janeway CA, Apt L, Gitlin D. Agammaglobulinaemia. Trans Assoc Am Physicians 1953;66:200-202.

8. Luzi G, Businco L, Aiuti F. Primary immunodeficiency syndromes in Italy: A report of the national register in children and adults. J Clin Immunol 1983;3:316-320. https:// doi.org/10.1007/bf00915792

9. Abolhassani H, Sagvand BT, Mirminachi B, et al. A review on guidelines for management and treatment of common variable immunodeficiency. Exp Rev Clin Immunol 2013:9(6):561-575. https://doi.org/10.1586/eci.13.30

10. Cunningham-Rundles C, Notarangelo LD, Feldweg AM. Pathogenesis of common variable immunodeficiency. In: Up To Date. https://www.uptodate.com/contents/ clinical-manifestations-epidemiology-and-diagnosis-of-common-variableimmunodeficiency-in-adults (accessed 12 August 2018).

11. Tam JS, Routes JM. Common variable immunodeficiency. Am J Rhinol Allergy 2013;27:260-265. https://doi.org/10.2500/ajra.2013.27.3899

12. Cunningham-Rundles $C$. The many faces of common variable immunodeficiency. Haematology 2012:301-305. https://doi.org/10.1182/asheducation-2012.1.301

13. Boileau J. Autoimmunity in common variable immunodeficiency: Correlation with lymphocyte phenotype in the French DEFI study. J Autoimmun 2011;36:25-32. https://doi.org/10.1016/j.jaut.2010.10.002

14. Aghamohammadi A, Farhoudi A, Moin M, et al. Clinical and immunological features of 65 Iranian patients with common variable immunodeficiency. Clin Diagn Lab Immunol 2005;12:825-832. https://doi.org/10.1128/cdli.12.7.825-832.2005

15. Cunningham-Rundles C, Bodian C, Good RA, et al. Common variable immunodeficiency: Clinical and immunological features of 248 patients. Clin Immunol 1999;92:34-48. https://doi.org/10.1006/clim.1999.4725

16. Hermaszewski RA, Webster AD. Primary hypogammaglobulinaemia: A survey of clinical manifestations and complications. Q J Med 1993;86:31-42.

17. Busse PJ, Razvi S, Cunningham-Rundles C. Efficacy of intravenous immunoglobulin in the prevention of pneumonia in patients with common variable immunodeficiency. J Allergy Clin Immunol 2002;109(6):1001-1004. https://doi.org/10.1067/ mai.2002.124999

18. Pourpak Z, Aghamohammadi A, Sedighipou L, et al. Effect of regular intravenous immunoglobulin therapy in patients with common variable immunodeficiency. J Microbiol Immunol Infect 2006;39(2):114-120.

19. Onbasi K, Gunsar F, Sin AZ, et al. Common variable immunodeficiency presenting as malabsorption due to giardiasis. Turk J Gastroenterol 2005;16(2):111-113.

20. Kalha I, Sellin JH. Common variable immunodeficiency and the gastrointestinal tract. Curr Gastroenterol Rep 2004;6(5):377-383. https://doi.org/10.1007/s11894004-0053-y

21. Webster ADB, Taylor-Robinson D, Furr PM, et al. Chronic cystitis and urethritis associated with ureaplasmal and mycoplasmal infection in primary hypogammaglobulinaemia. Br J Urol 1982;54:287-291. https://doi.org/10.1111/ j.1464-410x.1982.tb06977.x

22. Halliday E, Winkelstein J, Webster ADB. Enteroviral infections in primary immunodeficiency (PID): A survey of morbidity and mortality. J Infect 2003;46:1-8. https://doi.org/10.1053/jinf.2002.1066

23. Park JE, Beal I, Dilworth JP, et al. The HRCT appearances of granulomatous pulmonary disease in common variable immunodeficiency. Eur J Radiol 2005;54:359-364. https:// doi.org/10.1016/j.ejrad.2004.09.005

24. Vodjgani M, Aghamohammadi A, Samadi M. Analysis of class-switched memory B cells in patients with common variable immunodeficiency and its clinical implications. J Investig Allergol Clin Immunol 2007;17:321-328. 
25. Maglione PJ, Overbey JR, Radigan L, et al. Pulmonary radiologic findings in common variable immunodeficiency: Clinical and immunological correlations. Ann Allergy Asthma Immunol 2014;113:452-459. https://doi.org/10.1016/j.anai.2014.04.024

26. Gregersen S, Aalokken TM, Mynarek G, et al. Development of pulmonary abnormalities in patients with common variable immunodeficiency: Associations with clinical and immunologic factors. Ann Allergy Asthma Immunol 2010;104:503510. https://doi.org/10.1016/j.anai.2010.04.015

27. Morimoto Y, Routes JM. Granulomatous disease in common variable immunodeficiency. Curr Allergy Asthma Rep 2005;114:370-375. https://doi org/10.1007/s11882-005-0008-X

28. Washington K, Stenzel TT, Buckley RH, et al. Gastrointestinal pathology in patients with common variable immunodeficiency and X-linked agammaglobulinaemia. Am J Surg Pathol 1996;20:1240-1252. https://doi.org/10.1097/00000478-199610000-00010

29. Agarwal S, Mayer L. Pathogenesis and treatment of gastrointestinal disease in antibody deficiency syndromes. J Allergy Clin Immunol 2009;124:658-664. https:// doi.org/10.1016/j.jaci.2009.06.018

30. Malamut G, Verkarre V, Saurez F. The enteropathy associated with common variable immunodeficiency: The delineated frontiers with celiac disease. Am J Gastroenterol 2010;105:2262-2275. https://doi.org/10.1038/ajg.2010.214
31. Aukrust P, Muller F, Uueland T, et al. Decreased vitamin A levels in common variable immunodeficiency: Vitamin A supplementation in vivo enhances immunoglobulin production and down-regulates inflammatory responses. Eur J Clin Invest 2000;30:252-259. https://doi.org/10.1046/j.1365-2362.2000.00619.x

32. Cunningham-Rundles. Autoimmune manifestations in common variable immunodeficiency. J Clin Immun 2008;28(1):S42-S45. https://doi.org/10.1007/ s10875-008-9182-7

33. Chua I, Quinti I, Grimbacher B, et al. Lymphoma in common variable immunodeficiency: Interplay between immune dysregulation, infection, and genetics. Curr Opin Haematol 2008;15(4):368-374. https://doi.org/10.1097/ moh.0b013e328302c7b6

34. Abolhassani H, Aghamohammadi A, Imanzedah A. Malignancy phenotype in common variable immunodeficiency. J Invest Allergol Clin Immunol 2012;22(2):133-134.

35. Ameratunga R, Woon S-T, Gillis D, Koopmans W, Steele R. New diagnostic criteria for CVID. Exp Rev Clin Immunol 2014;10(2):183-186. https://doi.org/10.1586/1744 666X.2014.875274

36. Cunningham-Rundles C. How I treat common variable immune deficiency. Blood 2010;116:7-15. https://doi.org/10.1182\%2Fblood-2010-01-254417

Accepted 8 July 2021. 